\title{
Matemática e texto: práticas de numeramento num livro didático da educação de pessoas jovens e adultas*
}

\author{
PAULA RESENDE ADELINO \\ Colégio Técnico da Universidade Federal de \\ Minas Gerais, Belo Horizonte, MG, Brasil \\ MARIA DA CONCEIÇÃO FERREIRA REIS FONSECA \\ Universidade Federal de Minas Gerais, \\ Belo Horizonte, MG, Brasil
}

\section{PROPOSIÇÃO DO PROBLEMA}

A decisão de pesquisar livros didáticos dirigidos à Educação de Pessoas Jovens e Adultas (EJA) reflete as preocupações de um momento político do estabelecimento do efetivo direito à educação escolar conferido a esse público. Com a aprovação, em 2007, do Fundo de Manutenção e Desenvolvimento da Educação Básica (FUNDEB), que prevê a consideração das matrículas em EJA (ainda que com menor ponderação do que a atribuída às matrículas para outros níveis e modalidades) na redistribuição do fundo de base estadual, outros mecanismos de efetiva integração dessa modalidade ao projeto de educação da sociedade brasileira começam a ser consolidados, como a criação, em 2007, do Programa Nacional do Livro Didático para a Alfabetização de

* Texto apresentado no Grupo de Trabalho Educação de Pessoas Jovens e Adultas (GT18), da 35a Reunião Anual da Associação Nacional de Pós-Graduação e Pesquisa em Educação (ANPEd), realizada em Porto de Galinhas/Ipojuca (PE), de 21 a 24 de outubro de 2012. A pesquisa que subsidia este artigo teve apoio do Conselho Nacional de Desenvolvimento Científico e Tecnológico (CNPq). 
Jovens e Adultos (PNLA) e, em 2011, a extensão da distribuição de livros didáticos a todo o ensino fundamental da EJA. Tal distribuição demanda, entretanto, um processo de avaliação desses materiais didáticos, processo que tem esbarrado nas dificuldades para se estabelecerem critérios de avaliação, dada a ainda pequena reflexão sistemática sobre o livro didático na EJA.

Com efeito, embora as pesquisas sobre livros didáticos no Brasil venham aumentando nos últimos anos, é ainda modesto o repertório de estudos sobre materiais didáticos destinados à EJA. Parece razoável associar-se o aumento da produção de investigações acadêmicas sobre livros didáticos às mudanças que ocorrem, desde 1997, nas políticas públicas relacionadas a esse material no país, com a instituição da avaliação pedagógica no Programa Nacional do Livro Didático (PNLD).

A extensão desse programa de distribuição gratuita de livros didáticos para a modalidade EJA ocorre, contudo, mais de uma década depois, o que também se reflete na produção de reflexões sobre o tema, conforme revelou o levantamento que fizemos para identificar investigações sobre livros didáticos no campo da educação matemática de jovens e adultos: num corpus que reuniu os 176 trabalhos apresentados no Simpósio Internacional "Livro Didático: Educação e História”, que foi realizado na Universidade de São Paulo (USP) em 2007, os 233 trabalhos e pôsteres apresentados, de 1998 a 2011, no GT Educação de Pessoas Jovens e Adultas (GT18) da ANPEd e os 224 trabalhos e pôsteres apresentados, de 1998 a 2011, no GT Educação Matemática (GT19), apenas quatro trabalhos analisaram materiais didáticos voltados para a EJA (Adelino; Fonseca, 2007; Araújo, 2002; Funari, 2007; Moura; Freitas, 2007), dois deles dedicados ao ensino de matemática na EJA (Adelino; Fonseca, 2007; Araújo, 2002).

Esse fato reforçou nossa hipótese de que, apesar do grande incremento de pesquisas sobre livros didáticos, os materiais voltados para essa modalidade de ensino ainda são objetos de estudo pouco explorados nas pesquisas realizadas no Brasil. Levou-nos ainda a, elegendo esse tema para investigação, estruturar nossa análise com base na constituição de parâmetros que contemplassem as especificidades do público da EJA e do funcionamento dessa modalidade de oferta da educação básica.

A consideração dessas especificidades, bem como das delicadas relações e representações sociais que envolvem as iniciativas escolares de EJA, entretanto, nos obrigaria a evitar uma abordagem que restringisse a visão dessa modalidade de oferta da educação básica apenas considerando a redução do tempo destinado a cada etapa da formação escolar e que limitasse a compreensão dos processos de aprendizagem de seus estudantes focalizando tão somente aspectos cognitivos e sua dimensão individual.

Seria necessário, outrossim, contemplar a dimensão sociocultural da matemática que se pretende ensinar na escola, das práticas educativas destinadas a esse fim e dos modos como os sujeitos da EJA, aqui também considerados como sujeitos sociais, se apropriam do conhecimento escolar. As reflexões desencadeadas pela leitura de trabalhos que discutem a dimensão sociocultural das práticas matemáticas, inclusive daquelas que se constituem no espaço escolar, levaram-nos a eleger a identificação de tais práticas envolvidas nas atividades de livros didáticos da EJA como procedimento de análise e a reconhecer, no conceito de práticas de numeramento, uma 
boa ferramenta para operacionalizar tal análise, sem restringi-la ao levantamento de conteúdos contemplados ou de habilidades voltadas exclusivamente ao desempenho de tarefas matemáticas cujo domínio os livros pretenderiam promover.

Foi considerando, então, a contribuição de Baker, Street, Tomlin (2003); Fonseca (2009); Lave (1988); Mendes (2001, 2007); Soares (2006); Souza (2008); Street (1984) que vimos o conceito de práticas de numeramento apresentar-se mais produtivo para a análise que pretendíamos fazer do que o conceito de habilidades matemáticas, cuja utilização na literatura de educação matemática está mais relacionada à aquisição de competências cognitivas avaliadas por meio de comportamentos observáveis.

É por assumir como decisiva a consideração da dimensão sociocultural das práticas que envolvem conhecimentos, procedimentos ou critérios matemáticos, especialmente as que têm lugar no contexto escolar, que decidimos, nesta pesquisa, analisar, para além de habilidades matemáticas, práticas de numeramento que permeiam os (e que se pretende mobilizar e constituir por meio dos) livros didáticos de matemática voltados para a EJA.

\section{ESPECIFICIDADES E DESAFIOS DA EJA, MATERIAIS DIDÁTICOS, E PRÁTICAS DE NUMERAMENTO}

Para Vóvio (2001), na EJA, a necessidade de materiais didáticos é indiscutível. Um dos motivos destacados pela autora é o baixo poder aquisitivo, na maioria dos casos, dos estudantes e sua dificuldade em ter acesso à compra de livros ou outros materiais didáticos. Além disso, na maioria das vezes, os programas de EJA são realizados no período noturno, quando as bibliotecas não estão disponíveis e o professor fica, mais uma vez, sem acesso a acervos de materiais impressos para realização ou produção de atividades pedagógicas. É preciso considerar também que grande parte dos docentes trabalha em outros turnos e tem pouco tempo para a preparação de suas aulas. A falta de formação específica desses professores que atuam na EJA restringe suas possibilidades e recursos para elaboração de estratégias didáticas e de materiais para os alunos.

Por isso, este exercício de análise da abordagem que materiais didáticos de EJA conferem a conteúdos de matemática procura gerar subsídios para os desafios que envolvem educadores e educadoras na seleção e na utilização desses materiais; focaliza, em particular, o livro didático, material que educadores dessa modalidade de ensino são chamados a empregar no exercício de seu trabalho pedagógico, especialmente nesse momento em que o processo de distribuição de livros didáticos para a EJA começa a se estabelecer como política pública.

Para essa análise seria, entretanto, necessário considerar a importância do livro didático também pelo "seu aspecto político e cultural, na medida em que reproduz e representa os valores da sociedade em relação à sua visão da ciência, da história, da interpretação dos fatos e do próprio processo de transmissão do conhecimento" (Oliveira; Guimarães; Bomény, 1984, p. 11). Precisaríamos, ainda, atentar para a 
complexidade desse material apontada por Batista (2000, p. 553), advertindo que sua análise deve ser "mais do que descrever os conteúdos que expressam, seus pressupostos ideológicos, seus fundamentos teórico-metodológicos". É nessa perspectiva que optamos por pensar o livro didático de matemática da EJA como material concebido para desencadear, com sua utilização, a mobilização e/ou a constituição de determinadas práticas de numeramento que, por sua vez, também permeiam a própria produção desses materiais.

Ensinar, na EJA, conceitos da matemática escolar deveria ser um momento de inclusão, ou seja, uma oportunidade oferecida a alunas e alunos de apropriação de bens culturais, por meio de processos "de sistematização, de re-elaboração e/ou alargamento de alguns conceitos, de desenvolvimento de algumas habilidades e mesmo treinamento de algumas técnicas requisitadas para o desempenho de atividades heurísticas e algorítmicas" (Fonseca, 2002, p. 51).

Para isso, entretanto, seria necessário considerar um dos aspectos que Oliveira (1999) destaca como definidor da especificidade do público da EJA: sua condição de membros de determinados grupos culturais, não identificados com aqueles para os quais o projeto de escola da nossa sociedade foi originalmente elaborado.

Estudantes da EJA, grupo social "relativamente homogêneo no interior da diversidade de grupos culturais da sociedade contemporânea”(Oliveira, 1999, p. 59), configuram também um grupo cujas referências culturais são estranhas àquelas para as quais a escola tem sido tradicionalmente pensada. Esses alunos estranham a escola. $\mathrm{E}$ a escola estranha esses alunos. Eles estranham o modo de conhecer da escola, e a escola não reconhece e não sabe negociar com os modos de conhecer desses alunos. É preciso, pois, refletir sobre as estratégias de ensino e aprendizagem voltadas a esse público e sobre a própria natureza do conhecimento que a escola se propõe a ensinar.

As condições de trabalho ainda típicas da EJA escolar - curso com limitação de tempo; procedimentos didáticos e posturas pedagógicas não direcionadas e inadequadas ao público; infantilização das estratégias de ensino; professor sem formação específica; currículos pouco flexíveis; incômodo físico e estético, por causa de instalações e decorações voltadas para crianças; falta de materiais didáticos específicos para esse público - têm regulado o trabalho que se realiza nessa modalidade de oferta da educação básica muito mais que as recomendações oficiais de que a definição dos objetivos do ensino de matemática, bem como a seleção e a organização dos conteúdos e das estratégias didáticas, que devem ser estabelecidas em coerência com as demandas e expectativas próprias do público da EJA (Brasil, 2002).

Nesse contexto, à matemática escolar tem-se atribuído muito da responsabilidade pela evasão na EJA, não só pelo insucesso a que tem condenado muitos de seus estudantes, mas, principalmente, por não conseguir oferecer a seu público razões e motivações para permanecer no ambiente da escola.

Foi, contudo, na perspectiva de que a matemática escolar possa vir a se estabelecer como um conhecimento à disposição da formação humana de alunos e alunas, considerando aspectos de sua identidade sociocultural, de seus interesses, de suas 
necessidades, de suas curiosidades e de seus desejos, que nos dispusemos a analisar materiais didáticos elaborados para subsidiar o ensino de matemática na EJA.

Em particular, voltamo-nos para livros didáticos do segundo segmento do ensino fundamental, etapa na qual se iniciam os primeiros esboços de sistematização e formalização de conceitos, procedimentos e linguagem matemáticos. Com efeito, se a aquisição do conhecimento matemático "não se inicia, para o educando adulto, apenas quando ele ingressa num processo formal de ensino" (Duarte, 1986, p. 17), a experiência escolar deve ser capaz de contribuir para a apropriação, por esses alunos e essas alunas, de práticas de numeramento socialmente valorizadas e identificadas com a cultura escolar. Tais práticas se estruturam em linguagens, temas, procedimentos, relacionamentos, recursos de registro e critérios de avaliação próprios, para os quais os alunos e as alunas deverão conferir significados e relevância que permitam incorporá-los como recursos para compreender e transformar o mundo.

Neste trabalho, queremos, pois, destacar a pluralidade de práticas sociais "em torno das noções de quantificação, medição, ordenação e classificação em contextos específicos, em que os diversos usos dessas noções estão estreitamente ligados aos valores socioculturais que permeiam essas práticas" (Mendes, 2007, p. 23), a que designamos práticas de numeramento justamente para indicar que nossa abordagem não se volta exclusivamente para os aspectos técnicos dessas práticas, mas quer destacar o contexto sociocultural de sua produção como constituinte delas.

Baker, Street e Tomlin (2003), ao analisarem práticas de numeramento domésticas e práticas de numeramento escolares, destacam a operacionalidade desse conceito para contemplar a dimensão social da matemática. O conceito de social proposto por esses autores, porém, deve ser entendido "em termos de ideologia e discurso, relações de poder, valores, crenças, relações sociais e instituições sociais” (idem, p. 15, tradução nossa). Segundo os autores, as relações sociais

se referem a posições, papéis e identidades de indivíduos, em termos de numeramento, na relação com os outros. As instituições sociais e os procedimentos são constitutivos de controle, legitimação, status e supremacia de algumas práticas matemáticas em relação a outras, como se evidencia por meio de paradigmas e procedimentos aceitos e dominantes. (idem, ibidem, tradução nossa)

Como nosso estudo toma como corpus de análise práticas de numeramento que se constituem e se veiculam num suporte impresso, uma reflexão sobre as relações com a cultura escrita não poderia, porém, restringir-se a um certo "paralelismo" entre os conceitos de letramento e numeramento, ainda que tal relação nos ofereça boas perspectivas e ferramentas analíticas.

No estudo que ora apresentamos, dispusemo-nos, pois, a considerar as práticas de numeramento inseridas no âmbito das práticas de letramento, uma vez que nossa análise das atividades de um livro didático voltado para a EJA busca compreender relações que tais atividades supõem, permitem, reforçam ou questionam entre práticas matemáticas escolares e práticas de leitura e escrita de diversos tipos de textos. 


\section{PROCEDIMENTOS METODOLÓGICOS}

Para a realização de nossa análise, elegemos a coleção Viver, aprender (Educação de Jovens e Adultos, segundo segmento do ensino fundamental) (Mansutti; Onaga, 2004a, 2004b; Meirelles, 2004; Onaga, 2004), examinando as cinquenta atividades que estão inseridas nos capítulos que buscam propiciar a alunos e alunas oportunidades de compreensão dos números racionais.

A escolha desses capítulos deve-se não apenas à importância e à complexidade dos números racionais para a vida social e para a experiência matemática (Moreira, David, 2005), mas também à sutileza dos aspectos conceituais que envolvem sua abordagem no contexto escolar, em decorrência das tensões geradas pela multiplicidade de representações e de intenções associadas a essas representações, e pelas disputas entre argumentos que justificam, de um lado, a ênfase dada à memorização dos procedimentos e algoritmos para operar com esses números, e, por outro, os que defendem um destaque maior e mais cuidadoso ao seu aspecto sociocultural e às suas utilizações em contextos práticos. Dessa maneira, a abordagem escolar dos números racionais, de certa forma, faz convergir uma série de discussões que hoje permeia as reflexões do campo da educação matemática e também da EJA.

A opção por ter as atividades como corpus de análise baseia-se na compreensão do caráter tipicamente interacional desse gênero textual: nas atividades propostas num livro didático, os autores explicitamente convocam os estudantes a participarem da produção matemática, proporcionando uma oportunidade privilegiada de emergirem ou se configurarem práticas.

Selecionadas as atividades, elaboramos fichas (Quadro 1) para registro das principais características dessas atividades. Em cada ficha, uma atividade era reproduzida e então identificados: a sua localização nos volumes; o contexto em que se inseria; as habilidades matemáticas que julgávamos mobilizar ou pretender desenvolver; e as práticas de numeramento que conseguíamos perceber ali envolvidas.

Quadro 1- Ficha de identificação das atividades

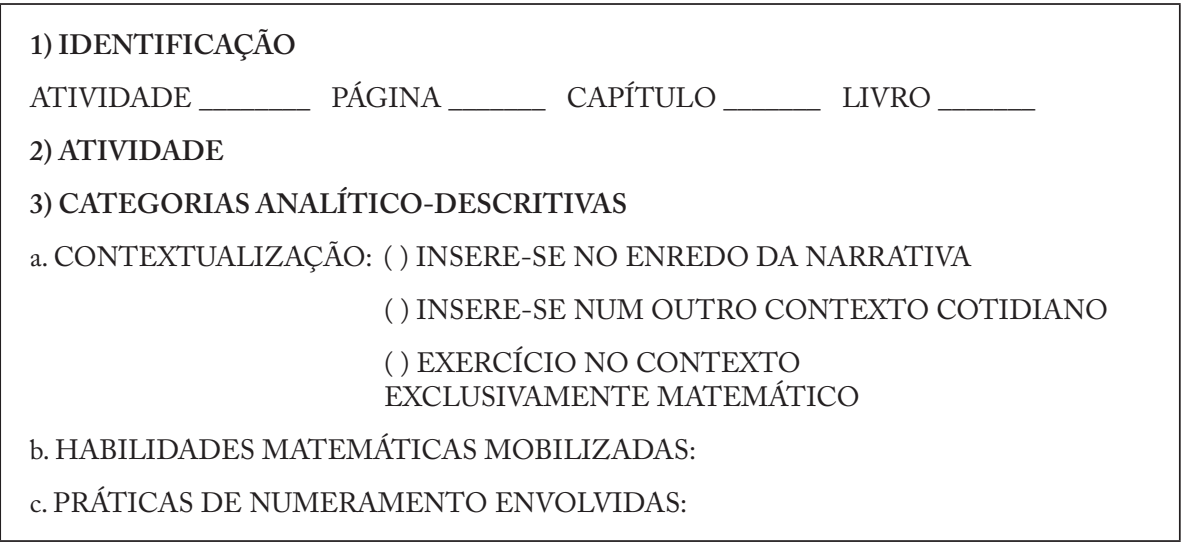

Fonte: Banco de dados da pesquisa.

Elaboração das autoras. 
Num primeiro exercício, distinguimos dois grupos de habilidades matemáticas: habilidades específicas da apropriação de conceitos, representações e operações com números racionais; e habilidades que envolvem procedimentos matemáticos mais gerais mobilizados no tratamento de diversos conteúdos escolares.

Além disso, identificamos também grupos de práticas de numeramento: práticas relacionadas à comunicação por meio da matemática; práticas que envolvem valorização e utilização do controle na produção de conhecimento matemático; práticas que supõem ou contribuem para o desenvolvimento de certa lógica de argumentação na defesa de posições; práticas que se referenciam na adoção da repetição como estratégia de aprendizagem; e práticas que se constituem na utilização de diversos recursos de cálculo matemático. $\mathrm{Na}$ caracterização de tais práticas, fomos, ainda, identificando aspectos que julgamos próprios da constituição de cada um desses grupos, conforme apresentado no Quadro 2.

\section{Quadro 2 - Aspectos característicos dos grupos de práticas}

\begin{tabular}{|l|l|}
\hline \multicolumn{1}{|c|}{ Práticas } & \multicolumn{1}{c|}{ Aspectos mobilizados } \\
\hline & A1. Apropriação de sistemas simbólicos de representação de quantidades contínuas. \\
& A2. Utilização de modelos e diagramas para representar ideias matemáticas. \\
& A3. Coleta, registro e análise de dados. \\
& A4. Leitura e interpretação de tabelas. \\
& A5. Construção de tabelas. \\
& A6. Preenchimento de tabelas. \\
A7. Leitura e interpretação de gráficos. \\
Relacionadas & A8. Construção de gráficos. \\
à Comunicação & A9. Valorização e uso da linguagem matemática para \\
por meio da & A10. Valorização das várias representaçães de um mesmo número racional. \\
matemática & A11. Interpretação e/ou produção de informaçôes estatísticas. \\
& A12. Valorização de diversos tipos de texto que fazem \\
& parte do cotidiano dos alunos da EJA. \\
& A13. Uso dos conhecimentos matemáticos como recursos para \\
interpretar, analisar e/ou resolver problemas em contextos diversos, \\
reconhecendo sua importância em nossa cultura. \\
A14. Reconhecimento dos números racionais em diversos contextos, seja como \\
medida, como quociente ou divisão indicada, como razão ou como operador.
\end{tabular}

(continua...) 
(...continuação)

\begin{tabular}{|c|c|}
\hline Práticas & Aspectos mobilizados \\
\hline $\begin{array}{l}\text { C } \\
\text { Relacionadas ao } \\
\text { Desenvolvimento } \\
\text { de certa lógica de } \\
\text { argumentação na } \\
\text { defesa de posições }\end{array}$ & $\begin{array}{l}\text { C1. Formalização de explicações e argumentos que } \\
\text { possam fundamentar respostas obtidas. } \\
\text { C2. Valorização do raciocínio lógico-dedutivo para alcançar explicações e conclusões. } \\
\text { C3. Valorização de provas e demonstrações matemáticas. } \\
\text { C4. Utilização de exemplos e/ou contraexemplos } \\
\text { para formular hipóteses e comprová-las. } \\
\text { C5. Desenvolvimento de postura crítica em relação ao resultado encontrado. } \\
\text { C6. Desenvolvimento da criatividade e da imaginação. } \\
\text { C7. Análise crítica de informações e opiniões veiculadas pela mídia, } \\
\text { suscetíveis de serem analisadas à luz dos conhecimentos matemáticos. }\end{array}$ \\
\hline $\begin{array}{l}\quad \mathrm{D} \\
\text { Relacionadas } \\
\text { à Adoção da } \\
\text { repetição como } \\
\text { estratégia de } \\
\text { aprendizagem }\end{array}$ & $\begin{array}{l}\text { D1. Valorização da repetição como uma maneira cultural de } \\
\text { aprendizagem em que as pessoas, e em especial os alunos da EJA, } \\
\text { constituem práticas em sua vida e adquirem conhecimentos. }\end{array}$ \\
\hline $\begin{array}{l}\quad \mathrm{E} \\
\text { Relacionadas } \\
\text { à Utilização } \\
\text { de diversos } \\
\text { recursos de cálculo } \\
\text { matemático }\end{array}$ & $\begin{array}{l}\text { E1. Utilização de procedimentos de cálculo mental. } \\
\text { E2. Utilização de procedimentos de cálculo escrito. } \\
\text { E3. Utilização de procedimentos de cálculo com a calculadora. }\end{array}$ \\
\hline
\end{tabular}

Fonte: Banco de dados da pesquisa.

Elaboração das autoras.

Construímos, ainda, quatro tabelas em que assinalamos as frequências de habilidades e aspectos identificados nas atividades. A construção dessas tabelas auxiliou-nos no reconhecimento de algumas tendências e mesmo de certas ausências que procuramos analisar como componentes de práticas sociais e, como tal, marcadas por intenções, valores e referências culturais. Foi com base nessas tabelas e no tratamento que lhes conferimos que pudemos arquitetar a estrutura de nossa análise.

Neste artigo, vamos focalizar as discussões que tal análise oportunizou quando nos voltamos para as práticas relacionadas à comunicação por meio da matemática. Queremos apresentar, de modo especial, reflexões suscitadas quando da abordagem de um dos aspectos que se destacam nessas práticas, qual seja, a valorização de diversos tipos de texto que fazem parte do cotidiano extraescolar dos alunos e das alunas da EJA (Aspecto A12, no Quadro 2).

\section{TEXTOS E APRENDIZAGEM MATEMÁTICA}

As pesquisas objetivando tornar os alunos leitores competentes, realizadas ao longo dos últimos tempos, têm mostrado que o ato de ler está alicerçado na capacidade humana de compreender e interpretar o mundo (Smole, Diniz, 2001). Segundo as organizadoras de Ler, escrever e resolver problemas, 
a leitura constrói-se na interação entre o leitor e o texto por meio de um processo no qual o pensamento e a linguagem estão envolvidos em trocas contínuas. Ler é uma atividade dinâmica, que abre ao leitor amplas possibilidades de relação com o mundo e compreensão da realidade que o cerca, que lhe permite inserir-se no mundo cultural da sociedade em que vive. (idem, p. 70)

Cabe, no entanto, referenciando-nos nas reflexões de Street (1984) sobre letramento, observar que a inserção no mundo cultural por meio da leitura se efetiva porque vivemos numa sociedade grafocêntrica, em que até mesmo as relações sociais que não se valem da mídia escrita são, de alguma maneira, influenciadas pela cultura escrita.

É nesse sentido que, no contexto escolar, é preciso considerar como o fazem Kleiman e Moraes (1999), que a leitura não deve ser tomada como território exclusivo dos professores de língua. Todos os educadores, principalmente quando atuam no contexto escolar, estão engajados no propósito de favorecer a apropriação de uma cultura letrada, valorizada numa sociedade como a nossa.

As autoras de Leitura e interdisciplinaridade propõem, pois, que os docentes assumam explicitamente e operacionalizem esse propósito, desenvolvendo projetos interdisciplinares que confiram centralidade ao texto, nos quais o ensino da leitura enfoque questões de linguagem comuns às diversas disciplinas do currículo escolar. Nesse mesmo sentido, com o objetivo de estabelecer tarefas escolares que permitam integrar o trabalho de professores de todas as áreas, Neves et al. (2007, p. 5) consideram que o acesso à leitura e à escrita deve ser visto "como objetivo e compromisso de todos os profissionais na escola, e não apenas do professor de Português, ainda que tais competências impliquem estratégias diferenciadas para a aprendizagem em cada área”.

Com efeito, há modos específicos de ler e produzir textos para falar de matemática, de geografia, de história etc. Smole (2001) destaca o valor da escrita nas aulas de matemática e ressalta que, apesar da pouca familiaridade dos professores com a utilização da produção de textos em matemática, tal produção é um componente essencial no processo de ensino-aprendizagem dessa disciplina. Smole e Diniz (2001) ressaltam a especificidade da escrita matemática, de sua combinação de sinais, letras e palavras que se organizam segundo certas regras para expressar ideias. Afirmam, ainda, que existe uma organização da escrita da linguagem matemática que nem sempre é equivalente à encontrada nos textos de língua materna, exigindo, então, um processo particular de leitura. As autoras afirmam

que os alunos devem aprender a ler matemática e ler para aprender matemática durante as aulas dessa disciplina, pois, para interpretar um texto matemático, o leitor precisa familiarizar-se com a linguagem e os símbolos próprios desse componente curricular, encontrando sentido no que lê, compreendendo o significado das formas escritas que são inerentes ao texto matemático, percebendo como ele se articula e expressa conhecimentos. (idem, p. 71) 
Fonseca e Cardoso (2005) discutem três possibilidades de relação entre atividade matemática e práticas de leitura em sala de aula: textos de matemática no ensino da matemática; textos de outros contextos no ensino da matemática; e textos que supóem ou mobilizam conbecimento matemático para o tratamento de questôes de outros contextos.

As reflexões de Smole (2001) e Smole e Diniz (2001), que destacamos anteriormente, inserem-se no âmbito da primeira dessas relações, que se refere à leitura de enunciados, de questões e de problemas matemáticos, além da leitura dos textos didáticos que abordam conteúdos escolares de matemática. As autoras destacam, porém, que o objetivo de tais textos didáticos, em geral, é a assimilação de determinada ideia, procedimento ou conteúdo que ali se encontra, para, posteriormente, responder a algumas perguntas. Nesse sentido, as práticas de leitura que nesse contexto se forjam são práticas típicas, e de certa forma exclusivas, dos modos de ler na escola.

A segunda relação, embora lide com textos de contextos não especificamente matemáticos, remete a situações em que os professores utilizam tais textos também visando ao ensino de matemática. Essa relação se evidencia em atividades didáticas que utilizam anúncios de produtos, mapas, contas de serviços públicos ou particulares, visores de aparelhos de medida etc., geralmente inseridos nos enunciados de problemas. Tais textos, ainda que não tenham sido criados especificamente para o ensino de matemática, aparecem ali com essa intenção. Fonseca e Cardoso (2005) advertem que, nessa relação, ainda se observa "o texto a serviço do ensino de matemática".

Apesar de reconhecerem o esforço em se promoverem situações de leitura em aulas de matemática, tanto por parte dos autores de textos didáticos quanto dos professores que trazem textos de outros contextos para essas aulas, Fonseca e Cardoso (2005) avaliam que a situação que se forja para sua leitura configura-se muitas vezes artificial, pois "o leitor é chamado a ler o texto tão somente para 'encontrar as informações mais importantes' que, na opinião do professor ou do autor do LD [livro didático], servirão de respostas para os itens do exercício"(idem, p. 69). As autoras se preocupam com o risco de não se estabelecer uma situação própria das leituras sociais, "em que o leitor procura no texto resposta para suas próprias indagações ou necessidades" (idem, ibidem).

Nesse mesmo sentido, Kleiman e Moraes (1999) advertem que todo texto utilizado nas práticas escolares sofre necessariamente um processo de didatização e acreditam que esse processo não se deve à simplificação ou obsolescência do texto, mas sim aos procedimentos metodológicos e didáticos a que o texto é submetido em aula.

É, por fim, na terceira relação que Fonseca e Cardoso (2005) parecem identificar o germe do esforço de "desescolarização" das práticas de leitura escolares, inclusive daquelas que se forjam nas atividades das aulas de matemática. Essa relação focaliza a leitura de textos que são produzidos com intenções outras que não "ensinar matemática" e que vêm para o contexto escolar também desvencilhados desse propósito, mas que demandam a mobilização de "ideias ou conceitos, procedimentos ou relações, vocabulário ou linhas de argumentação próprios do 
conhecimento matemático, sem que seu objetivo específico e declarado seja o de ensinar Matemática" (idem, p. 71). Segundo as autoras, nesses casos o tratamento das informações numéricas, que aparecem como parte da estrutura argumentativa do texto, não ocorre como "um treinamento de Matemática, aproveitando a desculpa do texto, mas como um esforço de interpretação para compreensão do texto, de sua intenção discursiva" (idem, ibidem, grifo do original).

Em nossa pesquisa, é a mobilização do aspecto A12, ou seja, a valorização de diversos tipos de texto que fazem parte do cotidiano extraescolar dos alunos da EJA, que contempla as relações entre atividade matemática e práticas de leitura. $\mathrm{Na}$ identificação das atividades que poderiam mobilizar tal aspecto, deparamo-nos com a sutileza da distinção entre duas das relações discutidas por Fonseca e Cardoso (2005) que se referem a textos de contextos não matemáticos: textos de outros contextos no ensino da matemática; e textos que supóem ou mobilizam conbecimento matemático para o tratamento de questóes de outros contextos.

No tratamento a que submetemos nosso corpus de análise, identificamos quatro atividades (AT) em que vimos o aspecto A12 ser mobilizado: AT13, AT18, o item 3.1 da AT3 e a AT7.

13. Miralva descobriu uma nova receita de doce. Essa receita dá para 8 porções. Miralva tem um problema: gostaria de preparar essa receita para 20 convidados.

\section{Doce cor-de-rosa}

8 porções

Ingredientes

1 lata de leite condensado

1 vidro de leite de coco

2 xícaras de leite

4 folhas de gelatina incolor

3 folhas de gelatina vermelha

Modo de fazer

Dissolva as folhas de gelatina no leite quente. Bata todos os ingredientes no liquidificador. Despeje em 8 taças e leve à geladeira.

a) Reescreva a receita, adequando as quantidades dos ingredientes ao número de porções que Miralva quer preparar.

b) Depois, justifique sua resposta. 
18. Mário foi à loja de materiais de construção e fez uma compra grande. Na saída derrubou tinta na nota fiscal, apagando alguns números. Com auxílio de uma calculadora, ajude Mário a descobrir os números que ficaram embaixo da tinta.

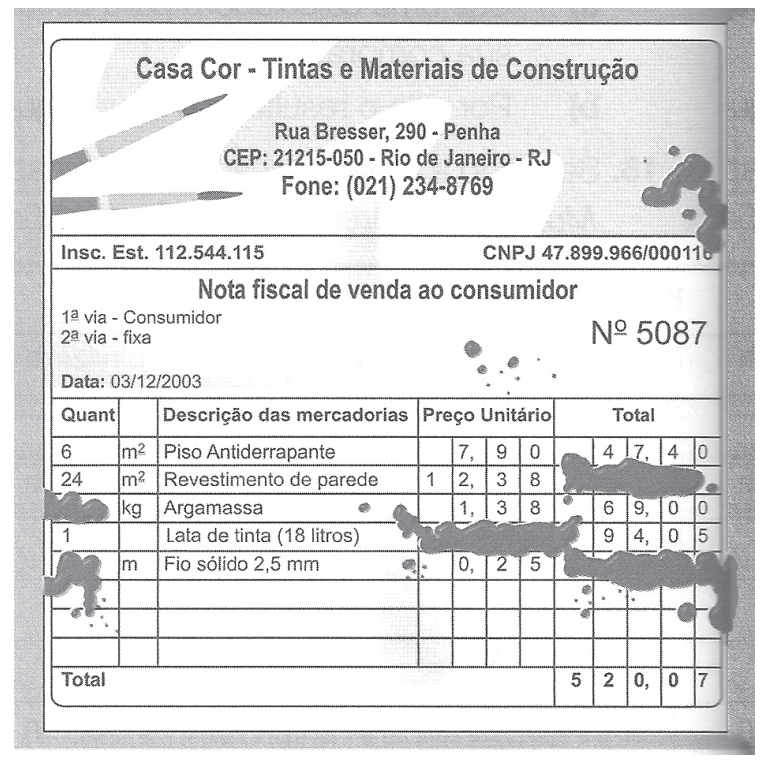

Figura 2 - AT18.

Fonte: Meirelles, 2004, p. 72.

Elaboração das autoras. 


\section{Reajustando valores}

3.1 Considere as manchetes de jornais que aparecem a seguir.

Passagens de ônibus serão

reajustadas em $20 \%$ a partir

da próxima segunda-feira
Gasolina sobe $15 \%$

a partir da zero hora

de amanhá

\section{Arrecadação do ICMS}

Reajuste dos bancários será de apenas 3\%, anuncia o sindicato no estado de São Paulo aumentou em $12 \%$ no último trimestre

Com base nas informações das manchetes, resolva os problemas a seguir, registrando as soluções e identificando os procedimentos utilizados para calcular as porcentagens.

a) Se a passagem de ônibus custa $R \$ 1,50$, qual será o seu valor após o reajuste?

b) Os preços da gasolina hoje são os seguintes:

Rio Branco - R\$2,520

Salvador $-\mathrm{R} \$ 2,20$

São Paulo - R $\$ 2,00$

Quais serão os novos preços da gasolina nessas cidades amanhã?

c) Qual será o salário de um bancário que atualmente ganha o equivalente a três salários mínimos, após o reajuste?

d) Qual foi o aumento na arrecadação do ICMS, sabendo-se que no trimestre anterior ela chegou a 100 milhões de reais?

Figura 3 - AT3.

Fonte: Mansutti; Onaga, 2004a, p. 71-72.

Elaboração das autoras. 


\section{Quem casa quer casa}

Marineide vai casar. Encontrou em um folheto de propaganda a planta de uma casa do jeito que procurava.

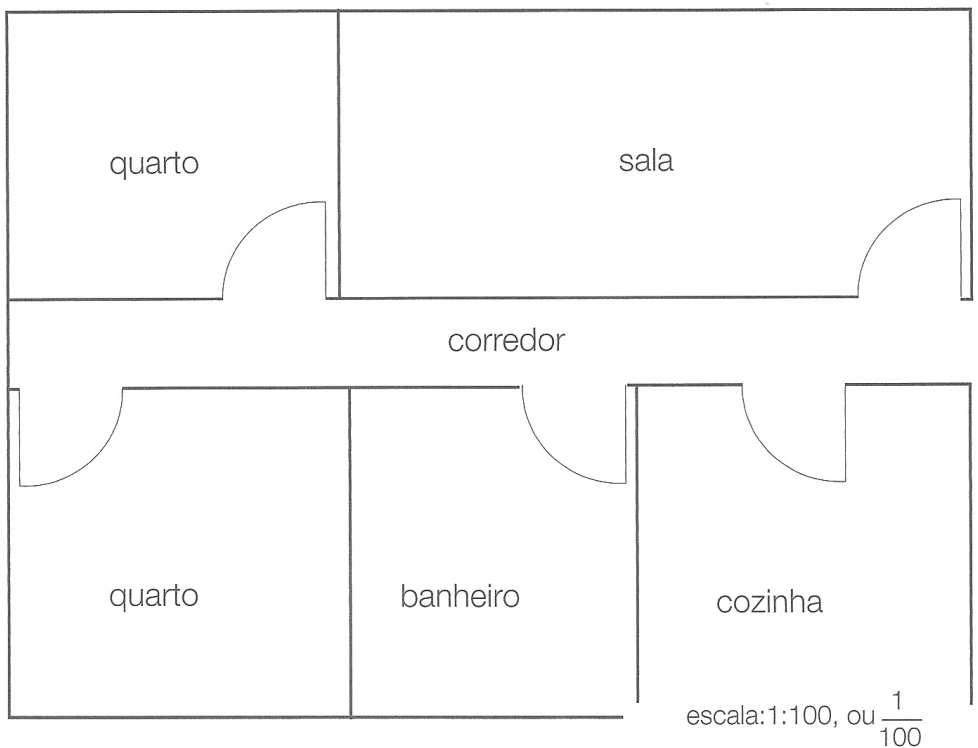

7.1. O que significa a escala $1: 100$ ou $\frac{1}{100}$ ?

7.2. Nessa planta, qual é a distância real, em metros, entre dois pontos:

a) Se a distância entre eles no desenho for $4 \mathrm{~cm}$ ?

b) Se a distância entre eles no desenho for $8 \mathrm{~cm}$ ?

c) Se a distância entre eles no desenho for $4,5 \mathrm{~cm}$ ?

d) Se a distância entre eles no desenho for $6,25 \mathrm{~cm}$ ?

7.3. Na frente da casa, Marineide quer fazer um jardim retangular de $3 \mathrm{~m}$ por $2 \mathrm{~m}$. Copie a planta em seu caderno e represente nela esse jardim, usando a mesma escala, ou seja, 1:100 ou $\frac{1}{100}$.

7.4. Utilize uma régua graduada para obeter as medidas na planta e determine as dimensões reais dos cômodos da casa.

7.5. Calcule a área total da casa.

7.6. Escreva um pequeno texto, descrevendo como será a casa de Marineide, a partir da planta desenhada.

Figura 4 - AT 7.

Fonte: Mansutti; Onaga, 2004a, p. 94.

Elaboração das autoras. 
As atividades selecionadas apresentam textos de diversos gêneros (receita culinária, nota fiscal de venda ao consumidor, manchetes de jornal, planta de uma casa).Tais textos são frequentes em portadores de fácil acesso para o cidadão comum, trabalhador(a), mãe/pai de família, consumidor(a). O fato de os textos que aqui focalizamos serem encontrados em atividades de um livro de matemática já sugere que a relação estabelecida é aquela que se caracteriza pelo uso de textos de outros contextos para o ensino de matemática. Entretanto, como as temáticas dos textos propostos, em geral, envolvem assuntos de interesse e de vivências do público da EJA, forjam-se, frequentemente, oportunidades de extrapolação das tarefas propostas pelos enunciados das atividades e de abertura para outras discussões e exploração das informações dos textos.

Vale comentar que a própria estruturação dos capítulos favorece a tematização de tais assuntos, uma vez que, apesar de os textos terem sido pouco mobilizados ao longo das atividades referentes aos números racionais, o primeiro contato dos estudantes com os conteúdos abordados ao longo dos capítulos dos livros Matemática e fatos do cotidiano (Mansutti; Onaga, 2004a, 2004b) é feito pela leitura de textos. Os conteúdos são desenvolvidos por meio da narrativa ou do comentário de algum fato ou tema que se encontra, com frequência, presente no cotidiano dos alunos e das alunas da EJA. Ademais, os conteúdos de matemática que se quer ensinar com os textos também são apresentados no intuito de aportar contribuições para a discussão mais informada daqueles fatos ou temas.

Além disso, ao longo dos dois volumes do livro de professores, encontram-se textos de fundamentação propostos pelas autoras para que também possam ser utilizados na sala de aula. Mansutti e Onaga (2004b) - autoras da coleção analisada - assumem que um dos papéis da educação matemática é constituir-se como espaço voltado ao aprendizado da leitura. $O$ posicionamento das autoras diante das relações entre ensino da matemática e da leitura, entretanto, revela como as duas relações descritas por Fonseca e Cardoso (2005) são, ao mesmo tempo, opostas e complementares.

Com efeito, depois de assumir o papel do aprendizado da matemática para o aprendizado da leitura, tanto pelo uso das narrativas no livro do estudante quanto pelas propostas de leituras complementares presentes no livro de professores, ou mesmo da introdução de textos nas atividades, Mansutti e Onaga (2004b, p. 18) afirmam, porém, que o objetivo da coleção é "a apropriação de conhecimentos matemáticos por meio da leitura, além das aulas expositivas seguidas de exercícios, estratégia didática comumente aplicada nessa disciplina".

É indiscutível a importância da leitura nas diversas disciplinas e nos diversos segmentos de ensino. Talvez, na EJA, essas práticas de leitura se tornem ainda mais importantes, levando-se em consideração os diversos tipos de texto e a grande frequência com que eles aparecem nas práticas sociais desses jovens e adultos em processo de escolarização. Além disso, como afirma Vóvio (2001), a maior parte dos alunos que inicia ou retoma seus estudos na juventude, ou na vida adulta, teve 
pouca oportunidade de analisar e conhecer as características dos textos escritos para além da escuta e manipulação de alguns deles, como jornais, revistas, cartas.

Por isso, ao analisar a estrutura e as opções metodológicas utilizadas para a elaboração dos livros didáticos da coleção Viver, aprender, do primeiro segmento do ensino fundamental para EJA, Vóvio (2001, p. 134) destaca que

a formação de um leitor autônomo e crítico, objetivo que delineia as atividades propostas nessa coleção, abrange aprendizagens para além da mera decodificação de sinais, implicando a compreensão do texto a partir do diálogo entre texto e leitor, a recriação de sentidos, o estabelecimento de relações e a mobilização de seus conhecimentos para dar coerência àquilo que foi lido. Para a elaboração de propostas de leitura e seleção de textos, tomou-se o aluno como sujeito dos processos constituintes do ato de ler, capaz de refazer o percurso do autor e trabalhar o texto no sentido de compreendê-lo e ressignificá-lo. Dessa forma, a aprendizagem da leitura na coleção "Viver, aprender" é tomada como exercício da cidadania, à medida que promove a criticidade e a plena inserção de jovens e adultos na sociedade da qual fazem parte.

Kleiman e Moraes (1999) consideram que uma proposta pedagógica deve contemplar necessariamente a inserção dos alunos em práticas sociais de uso da escrita com o objetivo de diminuir as desigualdades sociais. Além disso, estabelecem que, apesar do discurso oficial da escola reafirmar a importância da leitura, essa atividade, na prática, está vedada àqueles que não conseguem ir além do deciframento das palavras no texto. As autoras concluem que, nessa nossa sociedade injusta e desigual, faz-se necessário "formar indivíduos plenamente letrados, que possam seguir aprendendo pelo resto de suas vidas, capazes de utilizar a escrita para se fazerem ouvir, resistirem à propaganda, à mídia, atualizarem-se e serem críticos" (idem, p. 191).

Foi a percepção desse esforço - de, por um lado, construir estratégias para favorecer a apropriação de práticas de numeramento pela leitura de textos familiares e/ou interessantes para os sujeitos da EJA e, por outro, de disponibilizar recursos matemáticos que ampliem as práticas de leitura desses sujeitos - que nos levou a selecionar essas atividades que mobilizam textos de contextos e em gêneros diversos para contemplar, neste artigo, a relação entre textos e aprendizagem matemática, por sua importância na educação fundamental, principalmente quando seus educandos são pessoas jovens e adultas.

A análise dessa relação, bem como as outras análises que empreendemos ao longo da investigação, foi nos indicando a relevância que a coleção Viver, aprender confere ao caráter instrumental da matemática e, de modo especial, à sua função como recurso para registro, organização e comunicação de ideias.

Tal relevância configura a dimensão formadora que essa coleção atribui à matemática dentro do projeto educativo que assume. Esse projeto, contudo, é calcado na concepção do aluno e da aluna da EJA que fundamenta a coleção: sujeitos de cultura, na medida em que explicita o caráter cultural do conhecimento matemático e das 
relações que os sujeitos estabelecem com ele; sujeitos de aprendizagem, no esforço de abrir horizontes de aprendizagem nos processos de apropriação dos recursos forjados no âmbito de práticas de numeramento socialmente valorizadas; sujeitos de direitos, reconhecendo a legitimidade de seu desejo de acesso à informação, a novas perspectivas de leitura do mundo, ao conhecimento dos outros e de si mesmos e disponibilizando alternativas para sua realização.

\section{CONSIDERAÇÕES FINAIS}

A decisão de estudar uma coleção construída com base em uma concepção do sujeito da EJA de acordo com a que aqui assumimos - sujeito de cultura, de aprendizagem e de direitos - foi intencional, uma vez que é nessa concepção que temos identificado as potencialidades de análise da aquisição do conhecimento matemático como apropriação de práticas de numeramento.

Nesta pesquisa, porém, não focalizamos o livro didático sendo utilizado numa sala de aula. O que buscamos identificar foi a intencionalidade das atividades que são propostas aos alunos, considerando que elas não são colocadas num livro didático por acaso. Mais do que propiciar o domínio de determinadas habilidades matemáticas, as atividades mobilizam, constituem ou envolvem, de algum modo, certas práticas de numeramento que são carregadas de valores, crenças, atitudes, posicionamentos.

As intenções das autoras dos volumes da coleção Viver, aprender aqui analisados compõem um posicionamento político-pedagógico explicitado em diversos aspectos que identificamos ao longo da investigação, tais como:

- Nos modos de destacar a relação que existe entre as diversas representações dos números racionais - fracionária, decimal, percentual - e as diferentes oportunidades de utilizá-las;

- Na preocupação com um enfoque contextualizado da maioria das atividades propostas;

- $\mathrm{Na}$ escolha por preceder a introdução da representação fracionária à representação decimal dos números racionais, mas desenvolver seu ensino em constante relação;

- $\mathrm{Na}$ valorização diferenciada das diversas ideias relacionadas aos números racionais - medida, quociente ou divisão indicada, razão e operador;

- Na preocupação com a apropriação pelos alunos e alunas da EJA de práticas de numeramento que lidam com conceitos e informações estatísticas e com recursos do tratamento da informação;

- Na identificação de oportunidades de apropriação de práticas de numeramento por meio da leitura de textos familiares e/ou interessantes para os sujeitos da EJA;

- Na disponibilização de recursos matemáticos que ampliem as práticas de leitura desses sujeitos; 
- Na adoção de estratégias didáticas diversificadas e no papel que elas conferem ao aluno;

- Nos recursos de linguagem dos quais se utilizam e que são direcionados a certo público que, diversificado, social e culturalmente, apresenta suas peculiaridades na comunicação.

Essas escolhas acabam revelando posições de sujeito assumidas pelas autoras diante de um leitor presumido que elas constroem baseadas na visão que têm da EJA, do(a) educando(a) jovem e adulto e do(a) próprio(a) educador(a).

Outros tantos grupos de práticas de numeramento e os aspectos que os envolvem não foram contemplados em nossa análise, mas dispomos de um grande volume de material empírico pré-analisado para prosseguir com nossa reflexão. Parece-nos, da mesma forma, instigante poder desenvolver outro tipo de investigação que, focalizando o uso do livro didático em sala de aula, coloque em xeque nossas hipóteses e conclusões (sempre temporárias), brevemente apresentadas neste trabalho.

\section{REFERÊNCIAS}

Adelino, Paula Resende; Fonseca, Maria da Conceição Ferreira Reis. Livros didáticos de matemática na educação de jovens e adultos e o ensino de frações. In: Simpósıo Internacional "Livro Didático: Educação e História”. 2007, São Paulo. Anais... São Paulo: Centro de Memória da Faculdade de Educação da USP, 2007.

Araújo, Denise Alves. O ensino médio na educação de jovens e adultos: o material didático. In: Reunião Anual da Associação Nacional de Pós-Graduação e Pesquisa em Educação, 25., 2002, Caxambu. Anais... Caxambu, 2002.

Baker, Dave; StreEt, Brian; Tomlin, Alison. Mathematics as social: understanding relationships between home and school numeracy practices. For the Learning of Mathematics, Fredericton (NB, Canadá): FLM Publishing Association, v. 23, n. 3, p. 11-15, nov. 2003.

Batista, Antônio Augusto Gomes. Um objeto variável e instável: texto, impressos e livros didáticos. In: Abreu, Márcia Azevedo de (Org.). Leitura, história e história da leitura. Campinas: Mercado de Letras, 2000. p. 529-575.

BRASIL. Ministério da Educação e do Desporto. Secretária de Educação Fundamental: $5^{\mathrm{a}}$ a $8^{\mathrm{a}}$ série. Proposta Curricular para a Educação de Jovens e Adultos: segundo segmento do ensino fundamental: 5a a 8a série. Brasília, DF: SEF, 2002.

Duarte, Newton. O ensino de matemática na educação de adultos. São Paulo: Cortez. Autores Associados, 1986.

Fonseca, Maria da Conceição Ferreira Reis. Educação matemática de jovens e adultos: especificidades, desafios e contribuições. Belo Horizonte: Autêntica, 2002. 
. Conceito(s) de numeramento e relações com o letramento. In: Lopes, Celi Espasadin; Nacarato, Adair Mendes (Orgs.). Educação matemática, leitura e escrita: armadilhas, utopias e realidades. Campinas: Mercado das Letras, 2009. p. 47-60.

; CArdoso, Cleusa de Abreu. Educação matemática e letramento: textos para ensinar matemática e matemática para ler o texto. In: NACARATo, Adair Mendes; Lopes, Celi Espasadin (Orgs.). Escritas e leituras na educaşão matemática. Belo Horizonte: Autêntica, 2005. p. 63-76.

Funari, Sueli. Palavra e práxis nos livros didáticos de EJA. In: Simpósio Internacional "Livro Didático: Educação e História". 2007, São Paulo, Anais... São Paulo: Centro de Memória da Faculdade de Educação da USP, 2007.

Kleiman, Ângela; Moraes, Silvia. Leitura e interdisciplinaridade: tecendo redes nos projetos da escola. Campinas: Mercado das Letras, 1999.

Lave, Jean. Cognition in practice. Cambridge, UK: Cambridge University Press, 1988.

Mansutti, Maria Amábile; Onaga, Dulce Satiko. Matemática e fatos do cotidiano. Volume 2: livro do estudante. São Paulo: Global: Ação Educativa Assessoria, Pesquisa e Informação, 2004a. (coleção Viver, aprender).

. Matemática e fatos do cotidiano. Volume 2: livro do professor. São Paulo: Global: Ação Educativa Assessoria, Pesquisa e Informação, 2004b. (coleção Viver, aprender).

Meirelles, Helena Henry. Matemática e fatos do cotidiano. Volume 1: livro do estudante. São Paulo: Global: Ação Educativa Assessoria, Pesquisa e Informação, 2004. (coleção Viver, aprender).

Mendes, Jackeline Rodrigues. Ler, escrever e contar: práticas de numeramento-letramento dos Kaiabi no contexto de formação de professores índios do Parque Indígena do Xingu. 2001. Tese (Doutorado) - Instituto de Estudos da Linguagem, UNICAMP, Campinas, 2001.

. Matemática e práticas sociais: uma discussão na perspectiva do numeramento. In: Mendes, Jackeline Rodrigues; Grando, Regina Célia (Orgs.). Múltiplos olhares: matemática e produção de conhecimento. São Paulo: Musa Editora, 2007. p. 11-29.

Moreira, Plínio Cavalcanti; David, Maria Manuela Martins Soares. A formação matemática do professor: licenciatura e prática docente escolar. Belo Horizonte: Autêntica, 2005.

Moura, Tânia Maria de Mello; Freitas, Marinaide Lima de Queiroz. Processos interativos em sala de aula de jovens e adultos: a utilização do livro didático em questão. In: Reunião Anual da Associação Nacional de Pós-Graduação e Pesquisa em Educação, 30., 2007, Caxambu. Anais... Caxambu, 2007.

Neves, Iara Conceição Bitencourt; Souza, Jusamara; Guedes, Paulo; Schaffer, Neiva; Klusener, Renita. (Orgs.). Ler e escrever: compromisso de todas as áreas. Porto Alegre: Editora da UFRGS, 2007.

Oliveira, João Batista Araújo; Guimarães, Sonia Dantas Pinto; BoménY, Helena Maria Bousquet. A política do livro didático. Campinas: Editora da UNICAMP, 1984. 
Oliveira, Marta Kohl. Jovens e adultos como sujeitos de conhecimento e aprendizagem. Revista Brasileira de Educação, São Paulo: ANPEd; Campinas: Autores Associados, n. 12, p. 59-72, 1999.

Onaga, Dulce Satiko. Matemática e fatos do cotidiano. Volume 1: livro do professor. São Paulo: Global: Ação Educativa Assessoria, Pesquisa e Informação, 2004 (coleção Viver, aprender).

Smole, Kátia Cristina Stocco. Textos em matemática: por que não? In: ; Diniz, Maria Ignes (Orgs.). Ler, escrever e resolver problemas: habilidades básicas para aprender matemática. Porto Alegre: Artmed, 2001. p. 29-68.

; Diniz, Maria Ignez. Ler e aprender matemática. In: Smole, Kátia Cristina Stocco; Dinız, Maria Ignes (Orgs.). Ler, escrever e resolver problemas: habilidades básicas para aprender matemática. Porto Alegre: Artmed, 2001. p. 69-86.

SoARes, Magda Becker. Letramento: um tema em três gêneros. Belo Horizonte: Autêntica, 2006.

Souza, Maria Celeste Reis Fernandes de. Gênero e matemática(s): jogos de verdade nas práticas de numeramento de alunas e alunos da educação de pessoas jovens e adultas. 2008. (Doutorado em Educação) - Faculdade de Educação, Universidade Federal de Minas Gerais, Belo Horizonte, 2008.

Street, Brian Vincent. Literacy in theory and practice. Cambridge: Cambridge University Press, 1984.

Vóvio, Cláudia Lemos. Viver, aprender: uma experiência de produção de materiais didáticos para jovens e adultos. In: Ribeiro, Vera Masagão (Org.). Educação de jovens e adultos: novos leitores, novas leituras. Campinas: Mercado de Letras: Associação de Leitura do Brasil - ALB; São Paulo: Ação Educativa, 2001. p. 125-136.

\section{SOBRE AS AUTORAS}

Paula Resende Adelino é mestre em educação pela Universidade Federal de Minas Gerais (UFMG). Professora do Colégio Técnico da Universidade Federal de Minas Gerais (COLTEC-UFMG).

E-mail: pauladelino@yahoo.com.br

Maria da Conceição Ferreira Reis Fonseca é doutora em educação pela Universidade Estadual de Campinas (UNICAMP). Professora titular da Universidade Federal de Minas Gerais (UFMG).

E-mail:mcfrfon@gmail.com

Recebido em agosto de 2012

Aprovado em outubro de 2012 


\section{PAULA RESENDE ADELINO E MARIA DA CONCEIÇÃO FERREIRA REIS FONSECA}

\section{Matemática e texto: práticas de numeramento num livro didático da educação de pessoas jovens e adultas}

Este exercício de análise de atividades propostas num livro didático de matemática da Educação de Pessoas Jovens e Adultas (EJA) compõe um estudo desenvolvido no contexto das preocupações com a elaboração de parâmetros para a avaliação de materiais didáticos para esse público. Ao discutir como práticas de numeramento se constituem em atividades sobre números racionais, nossa análise pretende contemplar mais que esforços de promoção da aquisição de habilidades: quer problematizar a dimensão sociocultural das decisões pedagógicas e das práticas matemáticas para cuja apropriação um livro pretende contribuir. Focalizamos aqui práticas que relacionam leitura de textos e aprendizagem matemática, procurando estabelecer interlocução com reflexões sobre letramento e numeramento, sobre peculiaridades do ensino dos números racionais na educação básica e sobre as especificidades da relação dos alunos e das alunas da EJA com conhecimentos matemáticos e com práticas letradas.

Palavras-chave: educação de pessoas jovens e adultas; práticas de numeramento; práticas de leitura; livro didático.

\section{Mathematics and text: numeracy practices in a textbook addressed to youth and adult education}

This analysis of a group of activities proposed by a mathematics textbook addressed to Youth and Adult Education (EJA) is part of a study developed in the context of concerns about the development of parameters for the assessment of teaching materials for this public. By discussing how numeracy practices are constituted in school activities with rational numbers, our analysis intends not only to discuss the efforts to promote the acquisition of some skills, but also to problematize the sociocultural dimension of both pedagogic decisions and mathematics practices for whose appropriation the textbook intends to contribute. We focus on practices related to text reading and mathematics learning, seeking to establish a dialogue with reflections on: literacy and numeracy, peculiarities of the teaching of rational numbers and the specificities of the relations of young and adult students with mathematical knowledge and literate practices.

Keywords: youth and adult education; numeracy practices; reading practices; textbooks.

\section{Matemáticas y texto: prácticas de numeracia en un libro didáctico de la educación de personas jóvenes y adultas}

Este ejercicio de análisis de actividades propuestas en un libro didáctico de matemáticas de Educación de Personas Jóvenes y Adultas (EJA) compone un estudio desarrollado en el contexto de las preocupaciones con la elaboración de parámetros para evaluación de materiales didácticos para ese público. Al discutir cómo prácticas de numeracia se constituyen en actividades sobre números racionales, nuestro análisis va más allá de los esfuerzos para promoción de la adquisición de habilidades: problematiza la dimensión sociocultural de las decisiones pedagógicas 
y de las prácticas matemáticas para cuya apropiación un libro pretende contribuir. Destacamos las prácticas que relacionan lectura de textos y aprendizaje de matemáticas, buscando establecer interlocución con reflexiones sobre alfabetismo y numeracia, sobre las peculiaridades de la enseñanza de los números racionales en la educación básica y sobre la relación de los alumnos y de las alumnas de EJA con conocimientos matemáticos y con las de prácticas de lectura.

Palabras clave: educación de jóvenes y adultos; prácticas de numeracia; prácticas de lectura; libro didáctico. 